\title{
SISTEM PREDIKSI LULUS TEPAT WAKTU TUGAS AKHIR MAHASISWA MENGGUNAKAN SUPPORT VECTOR MACHINE (SVM)
}

\author{
Yogi Isro' Mukti ${ }^{1}$ \\ ${ }^{1}$ Program Studi Informatika, Sekolah Tinggi Teknologi Pagaralam \\ e-mail: *1yogie.isro.mukti@ sttpagaralam.ac.id,
}

\begin{abstract}
Abstrak
Tugas Akhir mahasiswa yang diselenggarakan merupakan proses akademik yang dilaksanakan oleh perguruan tinggi sebagai pengamalan terhadap tri dharma. Proses yang dilaksanakan mulai dari pendataan hingga proses bimbingan dilakukan dapat secara cepat dan efesien. Penelitian ini bertujuan untuk menghasilkan sebuah sistem pengelolaan tugas akhir yang memudahkan proses mulai dari pendaftaran, proses pemilihan pembimbing, penentuan judul, pembuatan lembar konsultasi hingga proses penilaian saat sidang, selain itu juga sistem yang mampu melakukan prediksi terhadap mahasiswa yang mengambil tugas akhir. Metode yang digunakan untuk melakukan prediksi yaitu support vector machine (SVM), sedangkan metode pengembangan sistem yang digunakan adalah Scrum metode ini dipilih karena proses pengembangan yang ringkas dalam menghasilkan perangkat lunak yang berkualitas dengan pembiayaan yang rendah. Penelitian ini menghasilkan sistem informasi tugas akhir yang dapat memudahkan dalam proses administrasi pengelolaan tugas akhir berdasarkan hasil pengujian yang dilakukan menggunakan katalon studio menyatakan dengan status lulus, sehingga sistem yang dibuat dapat digunakan, dan sistem yang digunakan mampu melakukan prediksi kelulusan mahasiswa tugas akhir. prediksi yang dilakukan menggunakan support vector machine ( $S V M)$, didapatkan bahwa parameter yang berpengaruh terhadap kelulusan tepat waktu pada mahasiswa adalah jumlah pertemuan $<=50 \%$ tidak lulus tugas akhir tepat waktu, dan untuk bimbingan $>=51 \%$ maka diprediksi Lulus Tugas Akhir tepat waktu.
\end{abstract}

Kata kunci : Sistem Prediksi; Tugas Akhir; Support Vector Machine

\begin{abstract}
The student's final project which is held is an academic process carried out by universities as an practice of the tri dharma. The process carried out starting from data collection to the guidance process can be carried out quickly and efficiently. This research aims to produce a final project management system that facilitates the process starting from registration, the process of selecting supervisors, determining the title, making consultation sheets to the assessment process during the trial, besides that it is also a system that is able to predict students who take the final project. The method used to make predictions is the support vector machine (SVM), while the system development method used is Scrum. This method was chosen because of the short development process in producing quality software with low funding. This research produces a final assignment information system that can facilitate the administrative process of final project management based on the results of tests carried out using a catalon studio stating that with a pass status, so that the system created can be used, and the system used is able to predict the final project student graduation. predictions made using a support vector machine (SVM), it was found that the parameters that affect the on-time graduation of students were the number of meetings $<=50 \%$ did not pass the final project on time, and for guidance $>=51 \%$, it was predicted that the final assignment would pass on time.
\end{abstract}

Keywords : prediction system; final project; Support Vector Machine 


\section{PENDAHULUAN}

Proses masa tuggas akhir merupakan masa dimana banyak mahasiswa terfokus dengan penyelsaian tugas akhir, agar dapat segera diselsaikan. Tugas akhir menjadi momen yang ditunggu-tunggu bagi mahasiswa namun juga menjadi sebuah momok menakutkan, bagi sebagian mahasiswa, yang bisa berakibat terlambatnya masa studi bagi mahasiswa. Salah satu momen yang dihadapi adalah proses administrasi, yang tidak kalah membuat stress bagi mahasiswa, karena banyaknya persyaratan yang diberikan oleh pihak kampus.

Banyak sistem tugas akhir yang dikembangkan [1], [2], [3], namun belum menerapkan sistem yang mampu memprediksi mahasiswa bisa lulus tepat waktu dalam mengerjakan tugas akhir, sistem yang ada hanya sebatas pada proses pemantauan, administrasi saja, belum menerapkan algoritma prediksi untuk melakukan predik terhadap mahasiswa yang melaksanakan tugas akhir. Padahal ini sangat penting, agar menjadi warning bagi mahasiswa agar bisa selesai tepat pada waktunya, yang tentu saja ini mempengaruhi terhadap poin dalam akreditasi program studi dimana salah satu poin penting berkaitan dengan lama studi mahasiswa.

Support Vector Machine (SVM) merupakan salah satu algoritma klasifikasi yang banyak digunakan yang mamapu mangatasi regresi linear maupun non linear [4]. SVM juga banyak digunkan untuk melakukan prediksi, seperti pemasaran langsung [5]. Oleh karena itu penelitian ini menggunakan SVM untuk melakukan prediksi mahasiswa yang mengambil tugas akhir.

\section{TINJAUAN PUSTAKA}

\subsection{Sistem Informasi}

Menurut John Ward dan Joe Peppard[6], menyebarkan informasi, menggunakan, mengumpulkan merupkan sistam informasi. Sedangkan menurut Ferdinan Magalin [7], kemampuan melakukan manajeerial untuk mengelola perusahaan dalam transaksi harian sebagai strategi dalam mengambil keputusan dan dapat memberikan informasi kepada pihak yang berkepentingan. Jadi bisa dikatakan bahwa sistem informasi merupakan sistem yang menyediakan [8] informasi bagi semua tingkatan dalam perusahaan, kapan saja diperlukan.

Sistem ini menyimpan, mengambil, mengubah, mengelola dan mengkomunikasikan informasi yang diterima menggunakan sistem informasi atau peralatan lainnya. Dari definisi di atas berarti sistem informasi sebagai sarana yang memungkinkan orang dan organisasi, memanfaatkan teknologi, mengumpulkan, memproses, menyimpan, menggunakan dan menyebarkan informasi sehingga hal ini bersangkutan dengan tujuan pemanfaatan teknologi informasi pada suatu organisasi.

\subsection{Penelitian Terdahulu}

Sistem informasi tugas akhir yang dibuat mustianti [1] dapat membantu dalam melakukan pemantauan mahasiswa bimbingan dan dapat membantu staf program studi dalam melakukan proses administrasi, dan telah dilakukan pengujian dengan black box testing berjalan dengan sesuai kebutuhan, selanjutnya dilakukan pengujian dengan MOS dari 3 pengguna mahasiswa, dosen dan admin dengan nilai rata-rata 98,22, namun memiliki kekurangan yaitu belum adanya menu berita acara untuk dosen memberikan penilaian, dan juga belum ada alert untuk informasi lama mahasiswa mengerjakan tugas akhir. 
Penelitian yang dilakukan oleh Suwita [2], melakukan pengembangan sistem informasi tugas akhir dengan menambahkan konsep content management system (CMS), sehingga proses menjadi lebih mudah dalam mengatur sistem yang dibuat, namun sistem yang dibuat belum memiliki sistem yang mampu melakukan prediksi terhadap kapan mahasiswa menyelsaikan tugas akhir.

Selanjutnya penelitian yang dilakukan oleh Dwi [3] tentang perancangan, analisis dan implementasi sistem informasi tugas akhir dengan tingkat kepuasan pengguna $70,5 \%$ dari 70 responden. Sistem yang dibuat juga belum bisa melakukan prediksi kapan mahasiswa dapat menyelsaikan tugas akhir tepat pada waktunya.

Berdasarkan penelitian terdahulu peneliti membuat sistem tugas akhir dengan menambahkan sistem prediksi yang mampu melakukan prediksi terhadap mahasiswa yang sedang melakukan tugas akhir, dengan menggunakan algoritma data mining yaitu Support Vector Machine (SVM).

\section{METODOLOGI PENELITIAN}

Penelitian ini menggunakan Metode Support Vectot Machine (SVM) untuk melakukan prediksi. Support vector machine (SVM) mengalami perkembangan yang sangat pesat [4], support vector machine (SVM) dapat mengatasi masalah klasifikasi dan regresi dengan linier ataupun nonlinier kernel yang dapat menjadi satu kemampuan algoritma pembelajaran untuk klasifikasi [9]. Selain memiliki banyak kemampuan yang telah disebutkan diatas, metode SVM juga memiliki kelemahan pada sulitnya pemilihan parameter SVM yang optimal, keakuratan klasifikasi atau regresi ditentukan oleh sekelompok parameter yang sesuai [10]

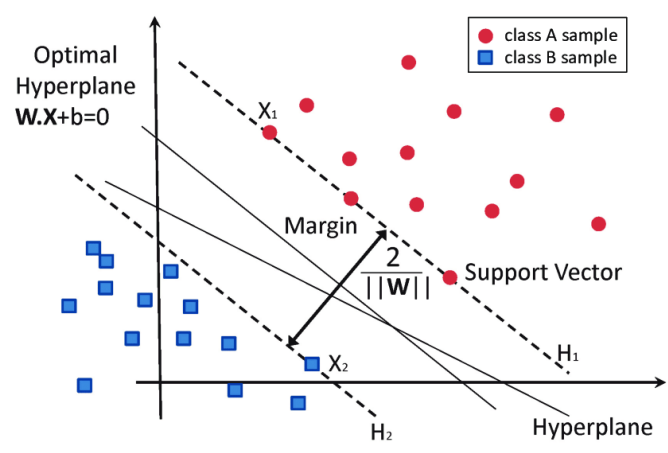

Gambar 1 Klasifikasi data Support Vector Machine

Kinerja SVM sangat tergantung pada pilihan yang memadai dari nilai-nilai parameter, termasuk misalnya, kernel dan parameter regularisasi. Pemilihan parameter SVM umumnya sebagai masalah optimasi di mana teknik pencarian digunakan untuk menemukan konfigurasi parameter yang memaksimalkan kinerja SVM [11]

Untuk metode pengembangan sistem sendiri digunakan scrum karena dapat digunakan untuk mengembangkan dan memelihara produk yang kompleks. Scrum adalah [12] sebuah kerangka kerja untuk mengembangkan, menghantarkan dan mengelola produk yang kompleks. Panduan ini berisi definisi Scrum yang terdiri dari peran-peran, acara-acara, artefakartefak, dan aturan-aturan yang menyatukan kesemuanya. Ken Schwaber dan Jeff Sutherland mengembangkan Scrum; Panduan Scrum ditulis dan disebarluaskan oleh mereka. Mereka berdua yang tetap mempertahankan Panduan Scrum.

Tiga peran yang ditentukan oleh kerangka Scrum. Peran-peran inilah yang membuka kekuatan Scrum dan memungkinkan nilai untuk disampaikan kepada pelanggan dan pemangku kepentingan dengan cepat [13]. 


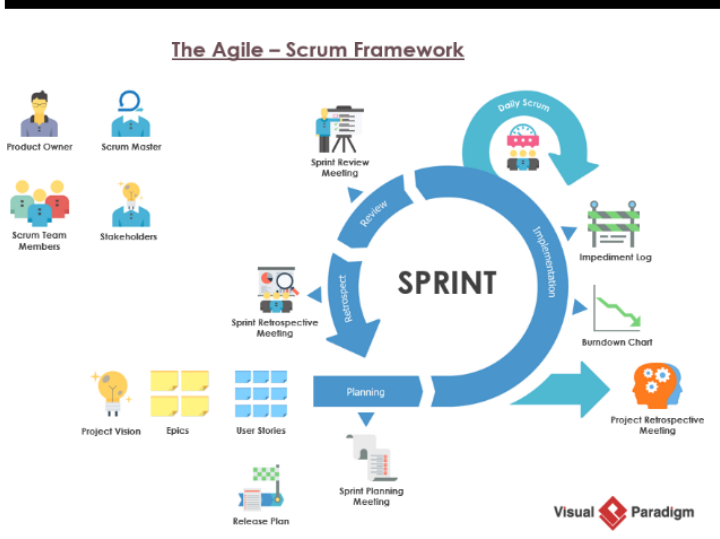

Gambar 2 Kerangka Kerja Scrum

Teknik pengumpulan data yang digunakan dalam penelitian ini melalui wawancara mendalam/indepth interview kepada informan terpilih. Untuk menganalisis hasil penelitian ini, maka dilakukan langkah-langkah sebagai berikut: Pengumpulan informasi, wawancara mendalam maupun obsevasi langsung; Reduksi data, memilih informasi mana yang sesuai dan tidak sesuai dengan masalah penelitian; Penyajian, data disajikan bisa dalam bentuk tabel, ataupun uraian penjelasan; dan tahap akhir adalah menarik kesimpulan.

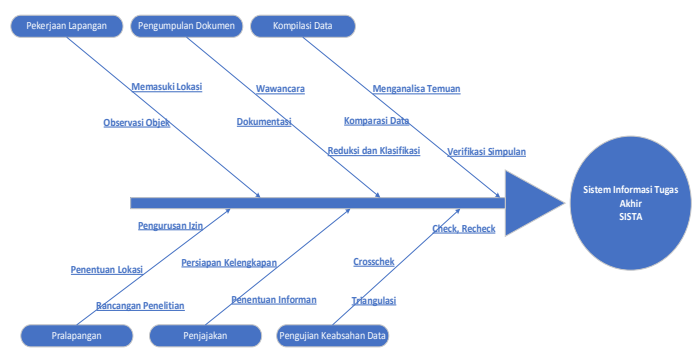

Gambar 3 Diagram Fishbone Alur Penelitian

\section{HASIL DAN PEMBAHASAN}

Penelitian yang dilakukan dengan menggunakan komputer dengan spesifikasi AMD Ryzen 5, RAM 8 GB, Sistem Operasi Windows 1064 bit. Aplikasi yang digunakan adalah Rapid Miner 9.7. Pengujian dilakukan menggunakan dataset mahasiswa Sekolah Tinggi Teknologi
Pagaralam, dengan parameter IPK, jumlah bimbingan 1 dan jumlah bimbingan 2 . Seperti yang ditampilkan pada gambar 4 . Dengan minimum bimbingan 6 dan maksimul 19 dengan rata-rata bimbingan 12,895 . Pada gambar 5 minimal bimbingan 1, maksimum 18 dan rata-rata didapatkan 11,211

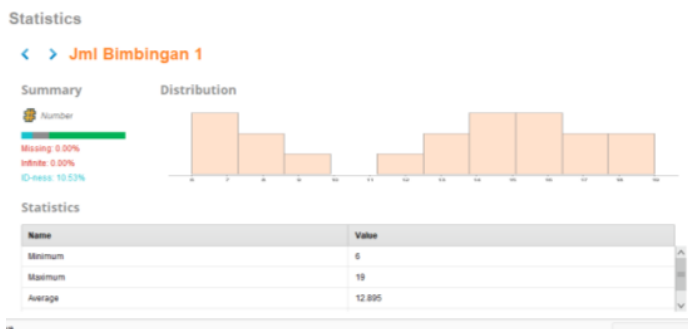

Gambar 4 Persentase Pertemuan dengan Pembimbing 1

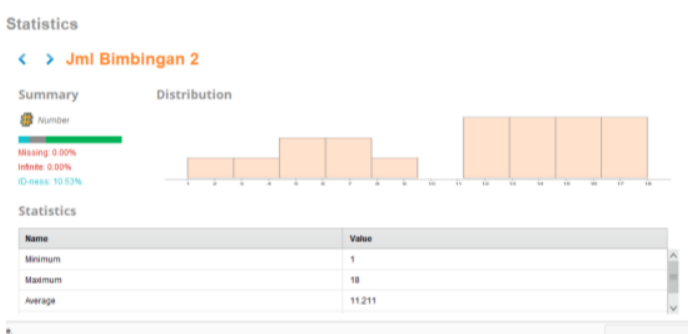

Gambar 5 Persentase Pertemuan dengan Pembimbing 2

Selanjutnya didapatkan 2 nilai yang berbeda, yakni lulus dan tidak lulus dari data yang dihitung dengan nilai persentase 68, 42 \% Lulus, dan 31,58\% Tidak Lulus.

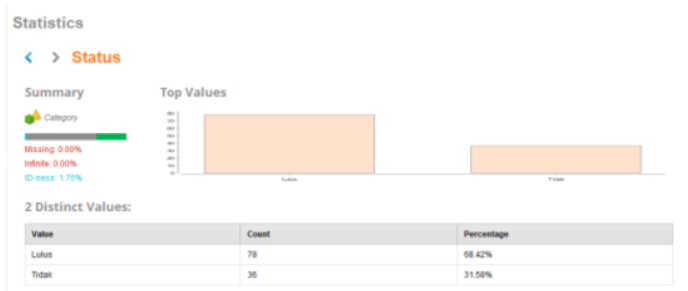

Gambar 6 Persentase Kelulusan Tugas Akhir

Berdasarkan nilai korelasi Support Vector Machine (SVM). Didapatkan nilai bimbingan 1 sebesar 0,717 , dan pada bimbingan 2 didapatkan nilai 0,691 dan IPK 0,902 . Seperti yang nampak pada tabel 1 . 
Tabel 1. Bobot berdasarkan korelasi

\begin{tabular}{|l|c|}
\hline \multicolumn{1}{|c|}{ Attribut } & Bobot \\
\hline IPK & 0,902 \\
\hline Jumlah Bimbingan 1 & 0,717 \\
\hline Jumlah Bimbingan 2 & 0,691 \\
\hline
\end{tabular}

Berdasarkan sistem prediksi yang dilakukan menggunakan support vector machine (SVM), didapatkan bahwa parameter yang berpengaruh terhadap kelulusan tepat waktu pada mahasiswa adalah jumlah pertemuan $<=50 \%$ tidak lulus tugas akhir tepat waktu, dan untuk bimbingan $>=51 \%$ maka diprediksi Lulus Tugas Akhir tepat waktu.

Tabel 2. Korelasi SVM

\begin{tabular}{|l|c|c|c|c|}
\hline \multicolumn{1}{|c|}{ Attribut } & IPK & $\begin{array}{c}\text { Jumlah } \\
\text { Bimbingan 1 }\end{array}$ & $\begin{array}{c}\text { Jumlah } \\
\text { Bimbingan 2 }\end{array}$ & $\begin{array}{c}\text { Status = } \\
\text { Lulus }\end{array}$ \\
\hline IPK & 1 & 0,708 & 0,35 & 0,717 \\
\hline Jumlah Bimbingan 1 & 0,708 & 1 & 0,756 & 0,902 \\
\hline Jumlah Bimbingan 2 & 0,35 & 0,756 & 1 & 0,691 \\
\hline Status = Lulus & 0,717 & 0,902 & 0,691 & 1 \\
\hline
\end{tabular}

Setelah didpatkan nilai SVM, langkah selanjutnya adalah menerapkan SVM kedalam sistem tugas akhir, yang dibangun berbasis aplikasi web, dan selanjutnya dilakukan pengujian terhadap sistem tugas akhir.

Dari pengujian yang dilakukan pada sistem informasi tugas akhir menggunakan katalon studio didapatkan hasil passed/ulus tes aplikasi, seperti yang terlihat pada gambar 1. Sehingga sistem dapat digunakan dan dijalankan dalam melakukan efesiensi proses administrasi tugas akhir.

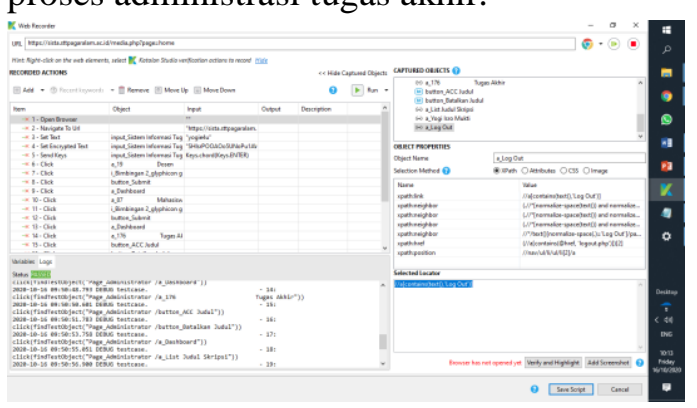

Gambar 7 Hasil Pengujian katalon studio
Gambar 8. merupakan tampilan halaman login pada aplikasi sistem tugas akhir, dengan memasukan username dan password yang terenskripsi.

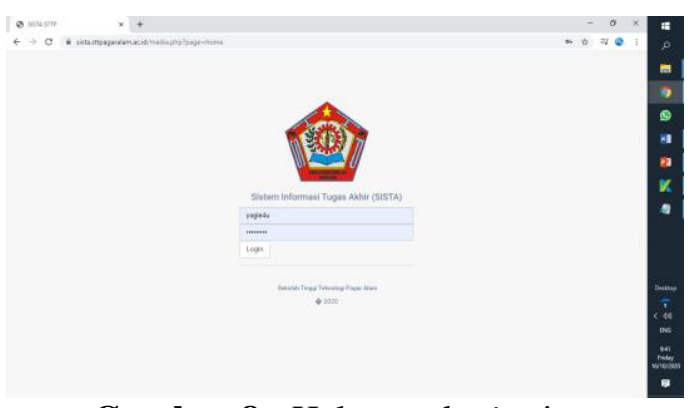

Gambar 8 Halaman login sista

Pada gambar 9 merupakan dashboard sistem kontrol sistem tugas akhir.

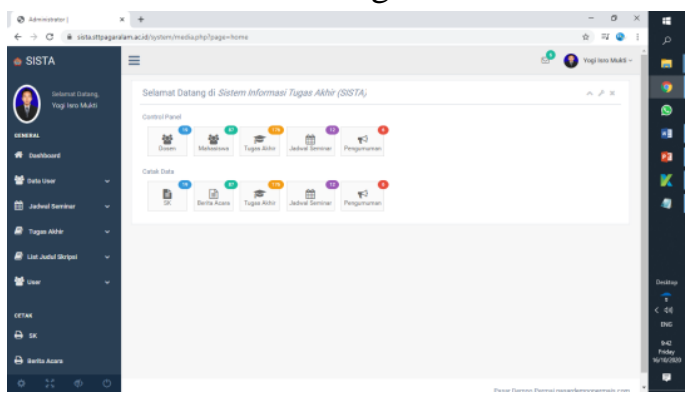

Gambar 9 Dashboard sista

Pada gambar 10 merupakan halaman bagi mahasiswa dengan menampilkan form ajuan judul, yang sekaligus menampilkan prediksi terhadap mahasiswa apakah akan lulus tugas akhir tepat pada waktunya atau tidak.

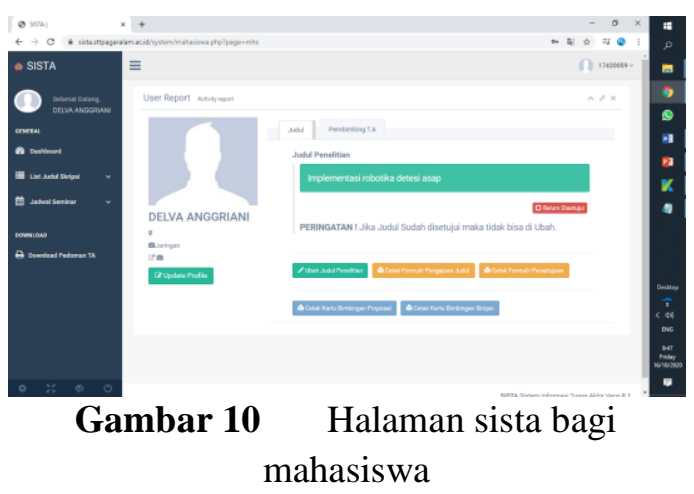




\section{KESIMPULAN}

Berdasarkan pembahasan di atas disimpulkan bahwa sistem tugas akhir yang diberi nama SISTA Sekolah Tinggi Teknologi Pagaralam, dapat berjalan dengan baik, dengan menerapkan sistem kontrol, dan juga menerapkan algoritma support vector machine (SVM), yang digunakan untuk melakukan prediksi terhadap mahasiswa yang sedang melaksanakan tugas akhir apakah akan tepat waktu atau tidak.

1. Sistem yang dibuat dapat berjalan sesuai dengan yang diharapkan

2. Penerapan algoritma Support Vector Machine (SVM), dapat digunakan untuk membantu memprediksi lulus tepat waktu tugas akhir.

3. Berdasarkan pengujian di atas tingkat akurasi SVM dapat diterima untuk melakukan prediksi

\section{SARAN}

Penelitian ini menggunakan algoritama Support Vector Machine (SVM), dalam membuat prediksi kelulusan tepat waktu tugas akhir, agar dapat meningkatkan akurasi SVM kedepannya bisa ditambahkan algoritma genetika, atau yang lain. Dan juga bisa menggunakan algoritma prediksi yang lain untuk meningkatkan akurasi prediksi lulus tepat waktu tugas akhir.

\section{DAFTAR PUSTAKA}

[1] M. Mustianti, I. B. Ketut Widiartha, and M. A. Albar, "Sistem Informasi Tugas Akhir Program Studi Informatika," $J$. Teknol. Informasi, Komputer, dan Apl. (JTIKA ), vol. 2, no. 1, pp. 19-29, 2020.

[2] FERRY STEPHANUS SUWITA, "Pengembangan sistem informasi tugas akhir dan skripsi (simita) di universitas komputer indonesia (unikom) artikel," 2016.

[3] D. Indah Lestari, R. Mardiani, and I. Wicaksana Siregar, "Analisis Perancangan dan Implementasi Sistem Informasi Tugas Akhir Berbasis Web untuk Mendukung Keunggulan
Bersaing," in Prosiding Seminar Hasil Penelitian \& Pengabdian kepada Masyarakat Unjani Expo (UNEX) I, 2019, pp. 1-3.

[4] D. R. Tobergte and S. Curtis, Learning with Kernels, vol. 53, no. 9. 2013.

[5] R. S. Wahono, "Penerapan Algoritma Genetika untuk Optimasi Parameter pada Support Vector Machine untuk Meningkatkan Prediksi Pemasaran Langsung," J. Intell. Syst., vol. 1, no. 2, pp. 115-119, 2015.

[6] J. Ward and J. Peppard, Strategic Planning for Information Systems. England, 2002.

[7] H. Saragih and Harisno, Renncana Strategis Teknologi Informasi (IT) dan Sistem Informasi (IS) Pada Proses Bisnis Perusahaan, 1st ed. Yogyakarga: Graha Ilmu, 2014.

[8] Y. I. Mukti, "Sistem Informasi Madrasah Aliyah Negeri Pagar Alam Berbasis Web," Indones. J. Comput. Sci., vol. 6, no. 2, pp. 192-205, 2018.

[9] Y. Kara, M. Acar Boyacioglu, and Ö. $\mathrm{K}$. Baykan, "Predicting direction of stock price index movement using artificial neural networks and support vector machines: The sample of the Istanbul Stock Exchange," Expert Syst. Appl., vol. 38, no. 5, pp. 5311-5319, 2011.

[10] C. Xiang, P. Qu, and X. Qu, "A chaotic time series forecasting model based on parameters simultaneous optimization algorithm," J. Inf. Comput. Sci., vol. 10, no. 15, pp. 4917-4930, 2013.

[11] T. A. F. Gomes, R. B. C. Prudêncio, C. Soares, A. L. D. Rossi, and A. Carvalho, "Combining meta-learning and search techniques to select parameters for support vector machines," Neurocomputing, vol. 75, no. 1, pp. 3-13, 2012.

[12] Sibarani, et.al., "Metode Scrum," Imp. J. Interdiscip. Res., vol. 2, no. 12, pp. 293-298, 2017.

[13] D. McKenna, The Art of Scrum. Pennsylvania, 2016. 